Combustion and emissions from cerium oxide nanoparticle dosed diesel fuel in a high speed diesel research engine under Low Temperature Combustion (LTC) conditions

Felix CP Leach ${ }^{\mathrm{a} *}$, Martin Davy ${ }^{\mathrm{a}}$, Barbara Terry ${ }^{\mathrm{b}}$

${ }^{\mathrm{a} D e p a r t m e n t}$ of Engineering Science, University of Oxford, UK; ${ }^{b}$ Energenics Europe Ltd, UK.

*corresponding author: felix.leach@eng.ox.ac.uk

Abbreviations: CA10 - Angle of 10\% mass fraction burned, DMS - Differential Mobility Spectrometer, DPF - Diesel Particulate Filter, EGR - Exhaust Gas Recirculation, FSN Filter Smoke Number, HC - Hydrocarbon, ISHC - Indicated Specific Hydrocarbons, ISNO - Indicated Specific $\mathrm{NO}_{\mathrm{x}}$, LTC - Low Temperature Combustion, MSOI - Main injection start of injection, $\mathrm{NO}_{\mathrm{x}}$ - Oxides of Nitrogen, $\mathrm{P}_{\mathrm{Max}}$ - Maximum cylinder pressure, PN - Particle Number, ppmv - parts per million (by volume), TWC - Three Way Catalyst, $\sigma-$ Standard deviation 


\title{
Combustion and emissions from cerium oxide nanoparticle dosed diesel fuel in a high speed diesel research engine under Low Temperature Combustion (LTC) conditions
}

\begin{abstract}
Cerium oxide $\left(\mathrm{CeO}_{2}\right)$ is widely used in three-way-catalysts (TWCs) in the catalytic oxidation of hydrocarbons (HC) and carbon monoxide (CO) as well as the catalytic reduction of $\mathrm{NO}_{\mathrm{x}}$. It has also had use as a fuel-borne catalyst in diesel fuel - particularly to promote diesel particulate filter (DPF) regeneration. The literature indicates that the catalytic effect of $\mathrm{CeO}_{2}$ might reduce $\mathrm{HC}$ emissions, reduce $\mathrm{NO}_{\mathrm{x}}$ formation, slow burn rates and reduce fuel consumption. In this work $8-10 \mathrm{~nm} \mathrm{CeO}_{2}$ particles in diesel are tested at two dosing levels $(5.7 \& 19.8 \mathrm{mg} / \mathrm{L})$ as a fuel-borne catalyst $(\mathrm{FBC})$ in a modern high speed single cylinder diesel engine at two operating points, one low load and one high load. The combustion and engine-out emissions are analysed and compared to the undosed diesel fuel. The results show that $\mathrm{CeO}_{2}$ reduces soot and THC emissions by up to $30 \%$ at part load under LTC but no significant differences are observed at high load. At high load a minor (2-5\%) reduction in $\mathrm{NO}_{\mathrm{x}}$ for a given EGR level is observed. No significant differences are seen in fuel consumption at either load point. At light load, a significant difference in the particulate size distribution is observed with fuels dosed with $\mathrm{CeO}_{2} . \mathrm{CeO}_{2}$ is observed to remove small particles under LTC conditions. In terms of the combustion parameters a reduction in maximum cylinder pressure of $2.5 \%$ at part load and an increase in ignition delay of up to $10 \%$ at high load are observed.
\end{abstract}

Keywords: Fuel-borne catalyst; low temperature combustion; ceria; cerium oxide; nanoparticle; emissions;

\section{Introduction}

Cerium oxide $\left(\mathrm{CeO}_{2}\right)$, also known as ceria, is a ceramic well known for its catalytic properties

[1]. Studies have shown it playing an active role not only in soot oxidation but also in $\mathrm{NO}_{2}$ reduction (to NO) due to its catalytic action [2]. Ceria is known to play a role in the catalytic oxidation of hydrocarbons (HCs) and carbon monoxide (CO) as well as the catalytic oxidation of soot at lower temperatures (than without the catalyst), particularly in the presence of $\mathrm{NO}_{2}$ [3]. Ceria nanoparticles also encourage faster evaporation of diesel fuel droplets by reducing the surface tension of the droplet [4]. Such beneficial properties have seen its use as a Fuel 
Borne Catalyst (FBC) deployed in so-called Diesel Particulate Filter (DPF) cleaners to promote shorter DPF regenerations - hence saving fuel and reducing $\mathrm{CO}_{2}$ emissions [5-7].

The catalytic properties of $\mathrm{CeO}_{2}$ have also seen its use in three-way catalysts (TWCs), of course alongside other metals, particularly for its oxygen storage capability under lean conditions [8].

Fuel-borne catalysts have been investigated for a long time as a way of promoting fuel oxidation in diesel engines hence increasing efficiency and decreasing fuel consumption. One common catalyst for this purpose is ferrous picrate based catalysts, which have been shown to give reductions in fuel consumption on some engines (3.3-4.2\% in the case of Zhu et al. [3]). Fuel-borne graphene quantum dots have also been shown to reduce fuel consumption by $14 \%$ when compared to undosed diesel fuel [9]. Similarly alumina nano-particles have been shown to reduce $\mathrm{HC}$ emissions by $9 \%$ from diesel engines under some circumstances [10]. Fuel-borne ferrous catalysts combined with ceria have also shown reductions in soot, $\mathrm{CO}$ and $\mathrm{HC}$ emissions by 20,27 , and $58 \%$ respectively when compared to undosed diesel fuel [11]. On the other hand fuel-borne graphene oxide-titanium dioxide nanoparticles have been shown to increase $\mathrm{CO}$ and $\mathrm{NO}_{\mathrm{x}}$ emissions by 15 and $27 \%$ respectively when compared to undosed diesel fuel [12].

Fuel-borne ceria nanoparticles were previously investigated by Wakefield et al. [13] who showed that such fuel-borne $\mathrm{CeO}_{2}$ nano-particles could reduce combustion peak pressure $\left(\mathrm{P}_{\mathrm{Max}}\right.$ ) due to an oxygen donation effect, and hence $\mathrm{NO}_{\mathrm{x}}$ emissions. $\mathrm{CeO}_{2}$ (and other rare earth oxides) can store and donate oxygen from their crystal lattices, which in an oxygen-lean environment (such as local fuel combustion in a diesel engine) will manifest itself as catalytic donation of oxygen. In addition Wakefield et al. [13] reported that fuel-borne $\mathrm{CeO}_{2}$ nanoparticles were seen to increase the combustion duration, which the authors state leads to a reduction in unburnt hydrocarbons and a decrease in fuel consumption of 8-9\%. It was also 
noted that over the long term, the fuel-borne $\mathrm{CeO}_{2}$ nano-particles due to their catalytic effect oxidise soot deposits within the cylinder and on the intake valves [13]. In contrast, Zhang et al. have reported increases in $\mathrm{NO}_{\mathrm{x}}$ emissions with fuel-borne $\mathrm{CeO}_{2}$ nano-particles [14].

Ceria nano-particles have seen widespread use in buses. For example Stagecoach, a large British bus operator, used Envirox ${ }^{\mathrm{TM}}$ (a popular brand of ceria nano-particles) for over 13 years in over 8,300 buses and coaches in UK and Canada. They report a 5\% reduction in fuel consumption which has saved an estimated 188,000 tonnes of $\mathrm{CO}_{2}$ from their fleet over eight years [15]. Other studies have confirmed the fuel economy benefits of ceria nano-particles in diesel, but have shown increases in other pollutants [16]. Pandey et al. showed some beneficial effect for ceria nano-particles and popular biodiesels such as Karanja and Jatropha [17]. In addition, Khalife et al. investigated the use of ceria nano-particles in water-diesel blends in a Ricardo E6 engine, and reported 5-16\% decreases in fuel consumption and 51, 45, and 27\% reductions in $\mathrm{CO}, \mathrm{HC}$, and $\mathrm{NO}_{\mathrm{x}}$ emissions respectively [18].

Much of the research work undertaken on ceria nano-particles was done on earlier generation diesel engines. Diesel combustion systems have changed substantially in recent years. These changes include (for example) higher injection pressures, piezo fuel injection systems, higher boosting pressures, and the use of simultaneously low $\mathrm{NO}_{\mathrm{x}}$ and low soot emission Low Temperature Combustion (LTC) modes [19]. The aim of this work was to investigate the effect of fuel-borne $\mathrm{CeO}_{2}$ nano-particles on combustion and emissions from a modern light duty diesel engine combustion system. In particular the following areas are specifically investigated:

1. Can the oxidative effect of the ceria reduce HC emissions in LTC?

2. Can the oxidative effect of the ceria reduce $\mathrm{NO}_{\mathrm{x}}$ formation at higher load?

3. Are the slow burn rates previously observed seen in a modern combustion system? 
4. Is the reduced $\mathrm{P}_{\mathrm{Max}}$ previously observed seen in a modern combustion system?

5. Does the ceria fuel-borne catalyst reduce fuel consumption?

\section{Experimental equipment and methodology}

\section{Engine and instrumentation}

The engine used in this study is a single-cylinder direct injection research diesel engine. The bottom-end is a Ricardo Hydra research engine. The engine configuration and its peripherals has been described in detail in previous publications [20-23]. The engine is not fitted with any aftertreatment (such as a DPF or any catalysts). Table 1 presents the details of the engine used.

\section{Table 1: Engine parameters}

\begin{tabular}{ll}
\hline Parameter & Specification \\
\hline Bore $\times$ Stroke & $83 \mathrm{~mm} \times 92.4 \mathrm{~mm}$ \\
Displacement & $500 \mathrm{~cm}^{3}$ \\
$\begin{array}{l}\text { Valves per } \\
\text { cylinder }\end{array}$ & 2 intake, 2 exhaust \\
Fuel system & Common rail \\
Fuel pressure & $400-2200$ bar \\
Piston bowl & Re-entrant \\
Fuel injector & 7-hole piezo \\
\hline
\end{tabular}

Crank-angle resolved cylinder pressure data were measured using a piezoelectric Kistler transducer and logged with a high-speed data acquisition unit (AVL Indicom) at a resolution of 0.1 CAD. Low frequency channels (at $1 \mathrm{~Hz}$ ) were logged using the CADET engine control system by Sierra-CP engineering.

Fuel flow measurements were carried out using both a gravimetric system and a coriolis fuel flow meter. The agreement between the two units is within $1 \%$ even at very low flow rates. Emissions measurements were done with a Horiba MEXA-ONE, smoke readings were taken 
using an AVL-415S smoke meter, and particle number measurements with a Cambustion DMS500. For reasons of commercial confidentiality, all emissions and ISFC results have been rescaled by an arbitrary value (and hence do not have a dimension).

The heat release and mass fraction burn results presented in this work were calculated using the standard package available in AVL Concerto software, using the signals from the incylinder pressure transducer and that of the shaft encoder. The heat release calculation was carried out over the range $-25-135 \mathrm{CAD}$ at a $0.1 \mathrm{CAD}$ resolution using Equation 1 below.

$$
Q_{i}=\frac{100}{\gamma_{i}-1} V_{i+1}\left[P_{i+1}-P_{i-1}\left(\frac{V_{i-1}}{V_{i+1}}\right)^{\gamma_{i}}\right]\left(x_{i}+1\right)
$$

where $\gamma$ is the polytropic coefficient, $\mathrm{V}$ is the instantaneous cylinder volume and $\mathrm{P}$ the ex $i$ is an empirically derived constant, which for diesels, is equal to 1 .

The engine was run at two speed-load points; one low speed, low load, where the engine enters LTC at high levels of EGR, and the other a higher speed, higher load point. Full details of the two test points are shown in Table 2. At both speed load points, a seven point EGR sweep was conducted in even steps across the range indicated in Table 2, with the upper end of the range limited by a smoke value. Each test point (at each EGR level) was repeated three times for each fuel run, and each fuel was repeated twice (see below). Inlet air, fuel, oil, and coolant are all temperature and pressure (and humidity) controlled to minimize environmental variability. High-frequency data was logged for 300 cycles, and low-frequency data (including the DMS500) was logged for three minutes. Each data point presented in the results presents a mean of those 300 cycle or three minute logs and their associated standard deviations.

\section{Table 2: Engine operating conditions}




\begin{tabular}{ccc}
\hline Test point & TP 1 & TP 2 \\
\hline Speed (rpm) & 1500 & 2500 \\
nIMEP (bar) & 3.8 & 17.7 \\
Rail pressure (MPa) & 58 & 147 \\
Number of injections per cycle (\#) & 5 & 5 \\
CA50 (deg)* & 10.5 & 13.3 \\
Intake T $\left({ }^{\circ} \mathrm{C}\right)$ & 55 & 40 \\
EGR rate $(\%)$ & $0-60$ & $0-15$
\end{tabular}

*CA50 was maintained constant with a closed-loop combustion controller by adjusting the main injection timing cycle-tocycle to achieve this. All other injections remained at constant timing with respect to the main injection.

\section{Test fuels}

The baseline fuel was an EN590 B0 standard diesel [24]. Table 3 shows the properties of this baseline fuel.

\section{Table 3: Base (undosed) diesel fuel composition.}

\begin{tabular}{ll}
\hline Cetane Number & 53.3 \\
Initial Boiling Point $\left({ }^{\circ} \mathrm{C}\right)$ & 172.5 \\
Final Boiling Point $\left({ }^{\circ} \mathrm{C}\right)$ & 362.0 \\
Density $@ 15^{\circ} \mathrm{C}(\mathrm{kg} / \mathrm{L})$ & 0.8312 \\
Aromatics $(\% \mathrm{~m} / \mathrm{m})$ & 23.9 \\
$\begin{array}{l}\text { Polycyclic Aromatics } \\
(\% \mathrm{~m} / \mathrm{m})\end{array}$ & 2.7 \\
Sulfur $(\mathrm{mg} / \mathrm{kg})$ & 7.8 \\
FAME $(\% \mathrm{v} / \mathrm{v})$ & $<0.1$ \\
\hline
\end{tabular}

This fuel was then dosed with cerium oxide nanoparticles 8-10 $\mathrm{nm}$ in diameter suspended in a hydrocarbon solution of similar molecular weight to diesel, and also containing a dispersant to avoid any particulate agglomeration. The aim was to achieve $5 \mathrm{mg} / \mathrm{L}$ and $20 \mathrm{mg} / \mathrm{L} \mathrm{CeO} 2$ nanoparticles in the fuel, these rates were chosen to be the manufacturers recommended dose 
$(5 \mathrm{mg} / \mathrm{L})$ and four times that dose in order to see the effect such a high dose might have. The achieved dosage rates are very close to this target, and are shown in Table 4.

Table 4: Dosed diesel fuel composition.

\begin{tabular}{ccc}
\hline $\begin{array}{c}\text { Target dose of } \\
\mathbf{C e O}_{2}\end{array}$ & $\begin{array}{c}\text { Measured dose of } \\
\text { Cerium (as metal) }\end{array}$ & $\begin{array}{c}\text { Achieved dose of } \\
\mathbf{C e O}_{2}\end{array}$ \\
$\mathrm{mg} / \mathrm{L}$ & $\mathrm{mg} / \mathrm{kg}$ & $\mathrm{mg} / \mathrm{L}$ \\
\hline 5 & 5.6 & 5.7 \\
20 & 19.4 & 19.8 \\
\hline
\end{tabular}

Fuel changes from one dosage of ceria nano-particles to another were followed by at least two hours of engine running at high load to ensure that all of the fuel lines were fully switched to new fuel. In addition the tests were all repeated in the order baseline, $5 \mathrm{mg} / \mathrm{L}$ ceria, $20 \mathrm{mg} / \mathrm{L}$ ceria (twice), $5 \mathrm{mg} / \mathrm{L}$ ceria, baseline in order to ensure confidence in the results - these three repeats are indicated as 'rpt' in the results plots. It can clearly be seen that there is excellent repeatability and that there is no drift or evidence of fuel cross-contamination in the results.

\section{Results}

\section{Low load}

Figure 1 shows the Indicated Specific $\mathrm{NO}_{\mathrm{x}}\left(\mathrm{ISNO}_{\mathrm{x}}\right)$ vs soot $(\mathrm{FSN})$ results for the engine at TP1 (1500 rpm, 3.8 bar nIMEP) across the EGR range (0-60\% - see Table 2). It can clearly be seen that at this test point, the engine enters a simultaneously low $\mathrm{NO}_{\mathrm{x}}$ and low soot regime, indicative of low temperature combustion (LTC) at $<0.03$ rescaled ISNO $_{x}$ at high levels of EGR (low levels of $\mathrm{ISNO}_{\mathrm{x}}$ ). The effect of the $\mathrm{CeO}_{2}$ is clear near the "knee point" of the $\mathrm{NO}_{\mathrm{x}}$ soot curve - with the ceria reducing soot emissions in the mid EGR range (0.03-0.6 rescaled $\mathrm{ISNO}_{\mathrm{x}}$ ) by $\sim 20 \%$ with $20 \mathrm{mg} / \mathrm{L}$ ceria. In addition the $\mathrm{CeO}_{2}$ also reduces the soot at the peak which is observed entering LTC by $\sim 50 \%$ with $20 \mathrm{mg} / \mathrm{L}$ ceria. In both cases the effect with $20 \mathrm{mg} / \mathrm{L}$ ceria is larger than the effect observed with $5 \mathrm{mg} / \mathrm{L}$ ceria. 


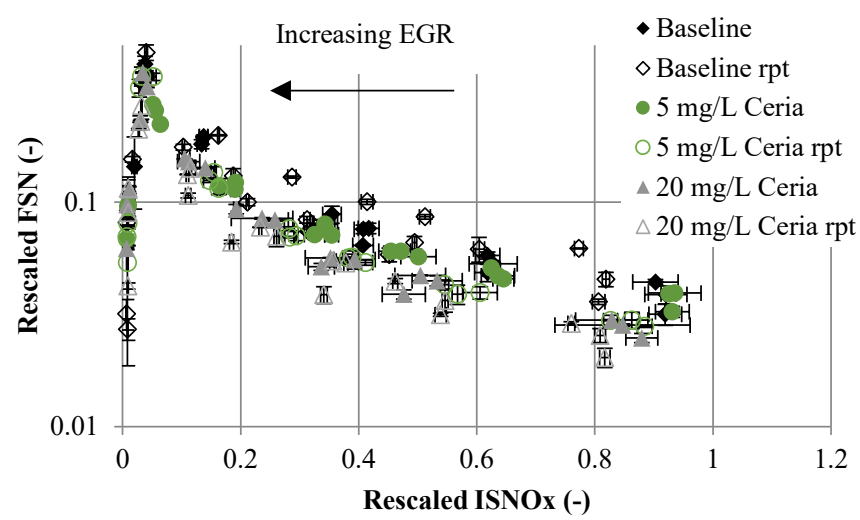

Figure 1: NOx-soot curve for the fuels at TP1 for all levels of EGR tested (0-60\%). The error bars correspond to $\pm \sigma$. (note the logarithmic y-axis).

Figure 2 shows the hydrocarbon (HC) emissions (ISHC vs ISNO between any of the fuels is noted across most of the $\mathrm{ISNO}_{\mathrm{x}}$ range, however mostly $(>0.1$ rescaled $\mathrm{ISNO}_{\mathrm{x}}$ ) the overall $\mathrm{HC}$ emissions are very low - as would be expected from a diesel engine. However, Figure 3 is a rescaled version of Figure 2 to show the area of LTC. Below about 0.03 rescaled $\mathrm{ISNO}_{\mathrm{x}}$, it is observed that the fuels dosed with ceria nano-particles emit lower levels of HCs than those without (a reduction of $\sim 20 \%$ for $5 \mathrm{mg} / \mathrm{L}$ ceria and $\sim 30 \%$ for $20 \mathrm{mg} / \mathrm{L}$ ) - showing that the oxidative effect of the ceria nanoparticles in reducing $\mathrm{HC}$ emissions at low combustion temperatures (when HC levels are increasing).

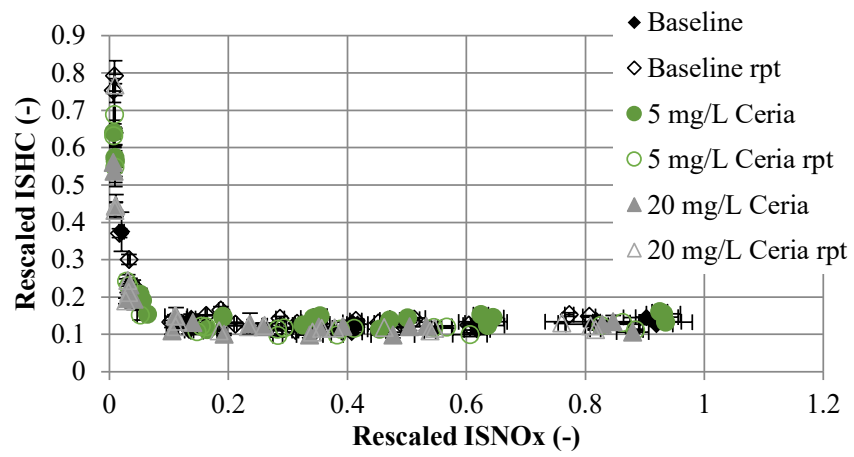

Figure 2: ISHC vs ISNO $\mathrm{O}_{x}$ for the fuels at TP1. The error bars correspond to $\pm \sigma$. 


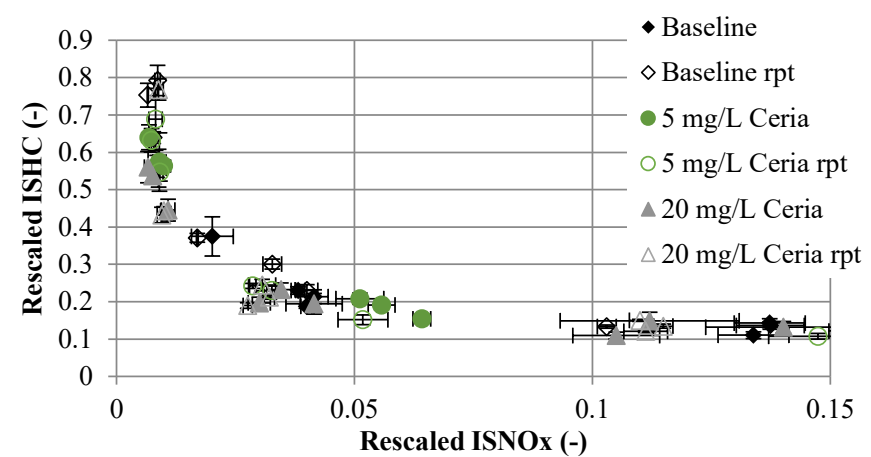

Figure 3: Rescaled Figure 2 showing the decrease in HC emissions seen from fuels dosed with $\mathrm{CeO}_{2}$ at the point where the $\mathrm{HC}$ emissions rise substantially. The error bars correspond to $\pm \sigma$.

Figure 4, Figure 5, Figure 6, and Figure 7 show the EGR rates, ISFC, ignition delays, and burn rate analysis across the range of EGRs tested. No significant differences are observed with any of the fuels tested at this test condition. These are in contrast to some of the high-load points that we present later in this paper (Figure 14 for example) and suggest a load and speed dependency of the effects of the ceria nanoparticles. As we note in our discussion below, the lack of a significant difference in ISFC is at variance with previously reported results in the literature.

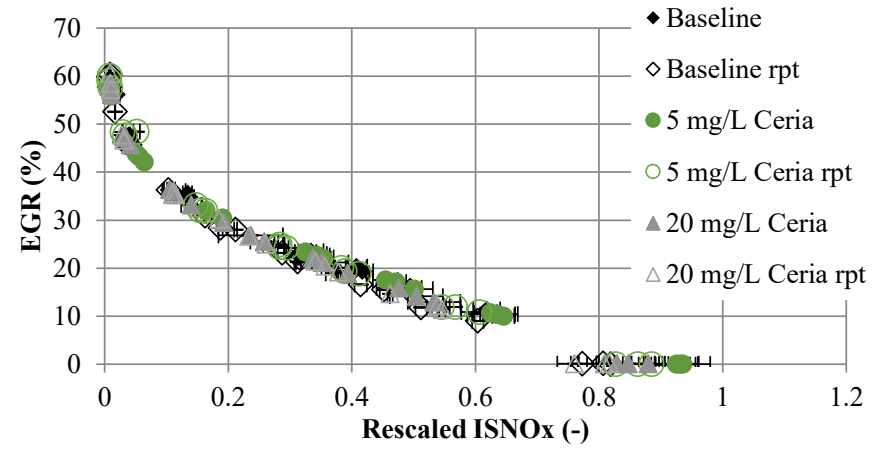

Figure 4: EGR vs ISNO for the fuels at TP1. The error bars correspond to $\pm \sigma$. 


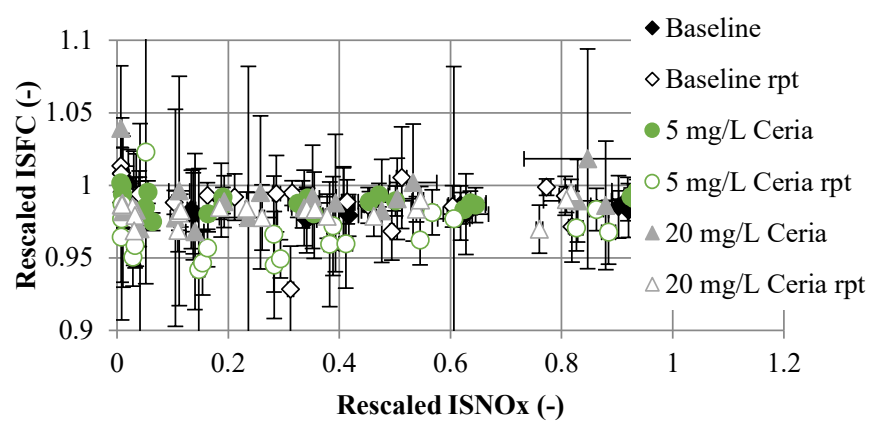

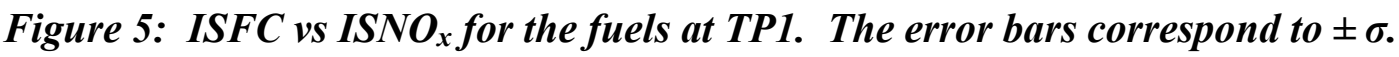

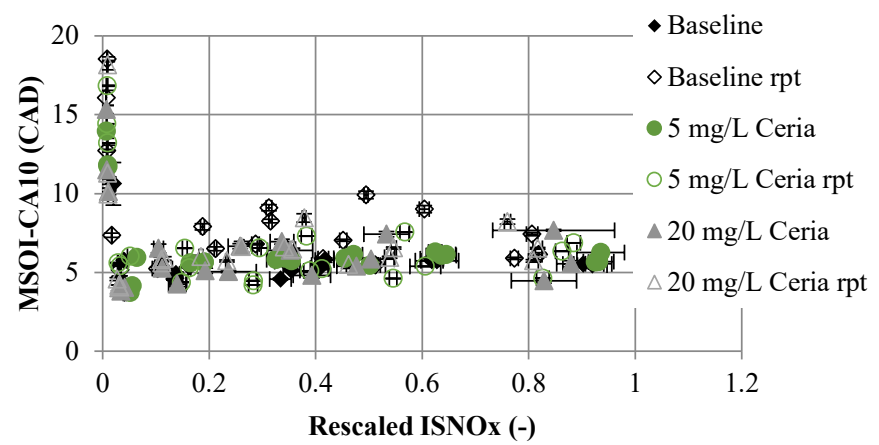

Figure 6: Ignition delay for the fuels at TP1. The error bars correspond to $\pm \sigma$.

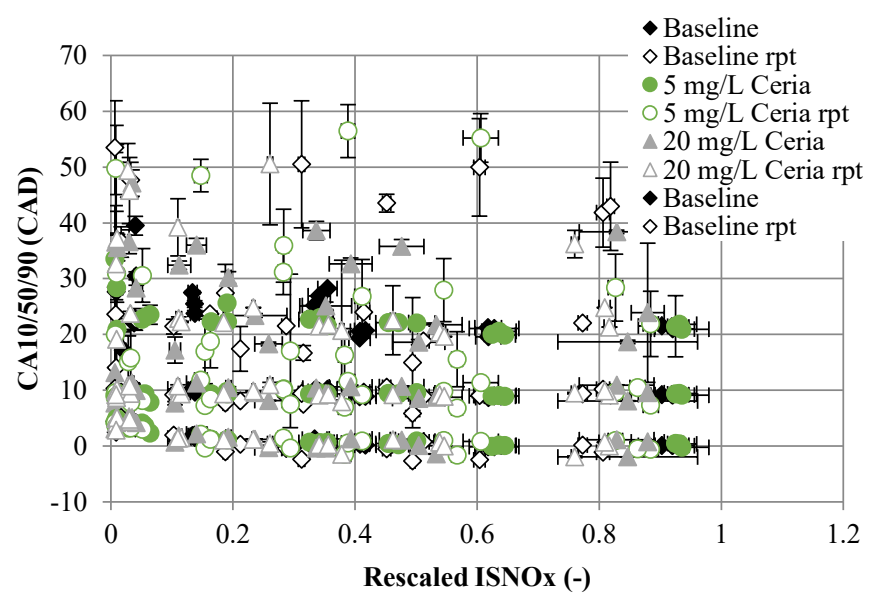

Figure 7: Burn rate analysis for the fuels at TP1. The error bars correspond to $\pm \sigma$.

Figure 8 shows the maximum cylinder pressure $\left(\mathrm{P}_{\mathrm{Max}}\right)$ at TP1. While there is some scatter in the results, it can be seen that the effect of the ceria, is to reduce the peak cylinder pressure by about $2.5 \%$, this is in line with previously reported results in the literature and is attributed to the oxygen donation effect described by Wakefield et al. [13]. 


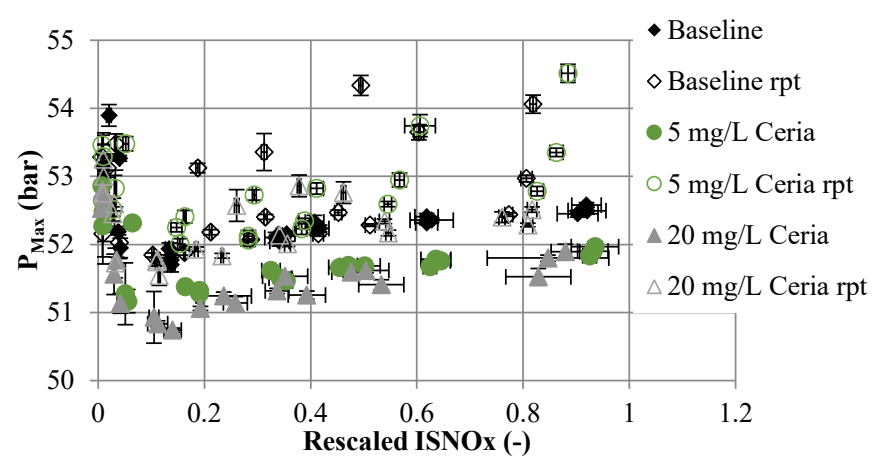

Figure 8: Maximum cylinder pressure for the fuels at TP1. The error bars correspond to $\pm \sigma$.

Figure 9 presents the $\mathrm{NO}_{2} / \mathrm{NO}_{\mathrm{x}}$ ratio across the EGR range; as expected the ratio increases as EGR is added, in line with the expected reduced combustion temperatures, and reduced overall $\mathrm{NO}_{\mathrm{x}}$ levels $[25,26]$. In addition, at the $20 \mathrm{mg} / \mathrm{L}$ level of ceria, a reduction in $\mathrm{NO}_{2} / \mathrm{NO}_{\mathrm{x}}$ ratio is observed below about 0.3 rescaled $\mathrm{NO}_{\mathrm{x}}$ - perhaps indicative of the reductive effect of ceria.

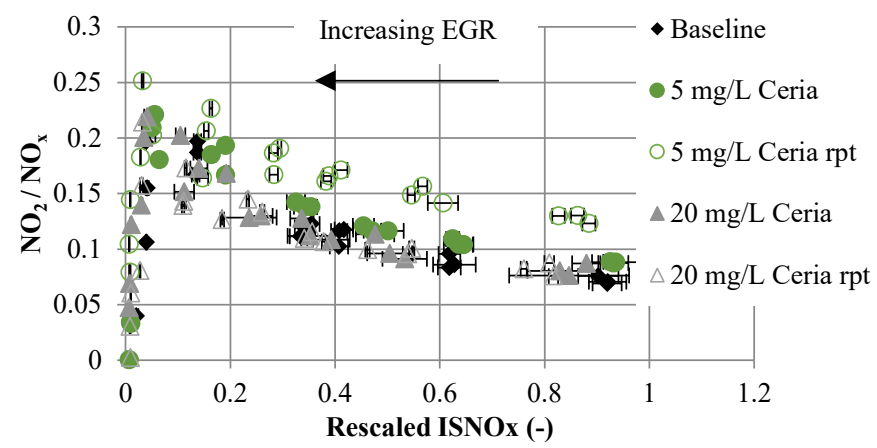

Figure 9: $\mathrm{NO}_{2} / \mathrm{NO}_{x}$ ratio vs ISNO for the fuels at TP1. The error bars correspond to $\pm \sigma$.

Figure 10 shows the particle size distributions for the fuels at TP1, $60 \%$ EGR. The effect of the ceria nanoparticles is marked here; the wide size distribution from $15-65 \mathrm{~nm}$ associated with LTC for the baseline fuel is completely transformed into a mono-modal distribution at $\sim 65 \mathrm{~nm}$. This is independent of ceria dosing level. This is indicative of the oxidative effect of the ceria, at low temperatures transforming the size distribution in LTC into one that is very 
similar to the higher temperature cases (i.e. higher levels of soot oxidation) - i.e. lower EGR rates - which are very similar (in trends) to those seen in Figure 19, and omitted here for clarity.

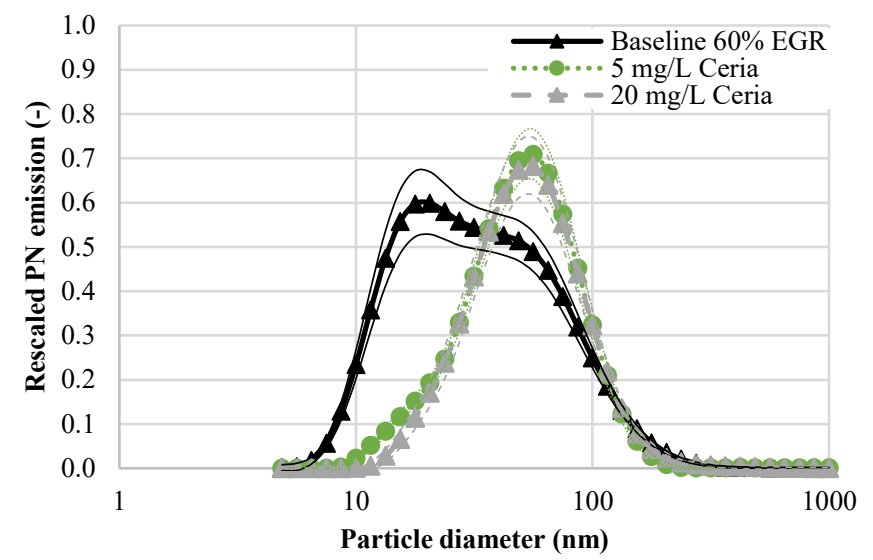

Figure 10: Particle size distributions for the fuels at TP1, 60\% EGR. The narrow bands correspond to $\pm \sigma$.

It is also worth observing that a very good correlation was seen between the PN results obtained from the Cambustion DMS500 and the FSN results obtained from the AVL415 smoke meter.

\section{High load}

Figure 11 shows the $\mathrm{NO}_{\mathrm{x}}$-soot curve at TP2. As at TP1, at this higher speed and load point, it can be seen that in the mid-range of $\mathrm{ISNO}_{\mathrm{x}}$ (say $0.5-1.25$ ) there is a reduction in soot emissions for the fuels with ceria nano-particle dosing, again higher at the higher levels of dosing.

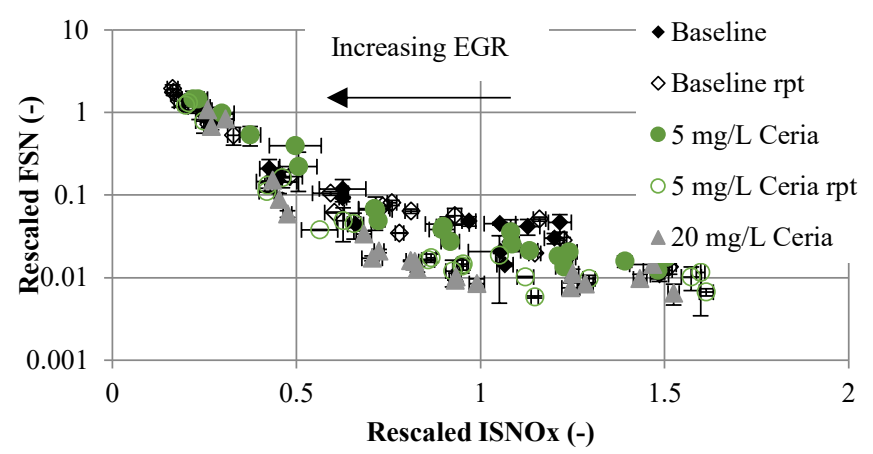

Figure 11: NO $\mathrm{O}_{x}$-soot curve for the fuels at TP2 (note the logarithmic y-axis). The error bars correspond to $\pm \sigma$. 
Figure 12 shows the $\mathrm{HC}$ emissions across the EGR range at TP2. It can be seen that there is no significant difference in $\mathrm{HC}$ emissions with ceria dosing, but overall the $\mathrm{HC}$ levels are very low, as would be expected from a diesel engine, operating at higher speed and very lean of stoichiometric where there is good mixing and excess oxygen available.

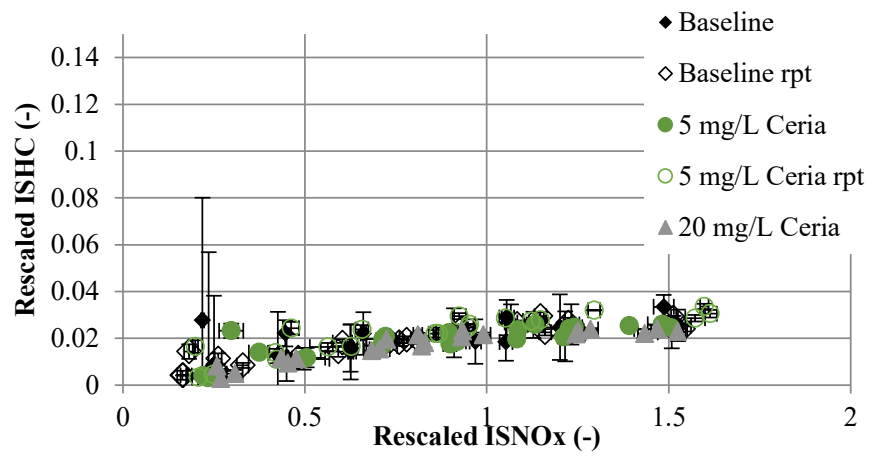

Figure 12: ISHC vs ISNO for the fuels at TP2. The error bars correspond to $\pm \sigma$.

At neither this high speed/load point, nor the low speed/load point were any differences seen in fuel consumption (ISFC) between any of the fuels tested, whether dosed with $\mathrm{CeO}_{2}$ or not (Figure 5 and Figure 13). This contrasts with other findings in the literature which have used similar dosing levels [10-12]. It is possible that the previously observed results in the literature are as a result of reduction in soot deposits in-cylinder - leading to an increase in efficiency, or less frequent (or shorter) DPF regeneration events - which temporarily cause an increase in fuel consumption. In the case of reduced deposits, the engine used in this work was a prototype single cylinder research engine, which did not have significant formation of deposits. In addition this engine was not fitted with a DPF (or indeed any exhaust aftertreatment) so any potential benefits to the DPF regeneration would not be seen in this work. Hence a lot of the reasons why a change in fuel consumption is seen in the literature (and in-service vehicles) are not present or applicable in this work, perhaps clarifying why this effect is seen more generally but not in the current study. 


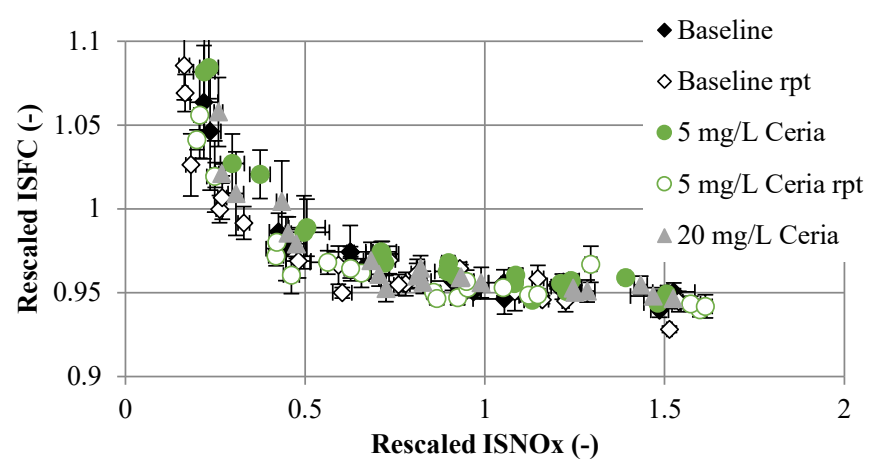

Figure 13: ISFC vs ISNO for the fuels at TP2. The error bars correspond to $\pm \sigma$.

Figure 14 shows the EGR levels plotted against $\mathrm{ISNO}_{\mathrm{x}}$ at TP2. It can be seen that with increasing levels of ceria, there is a reduction in $\mathrm{NO}_{\mathrm{x}}$ of 2 - $5 \%$ for a given EGR level, showing the reductive properties of ceria, are having an effect on the $\mathrm{NO}_{\mathrm{x}}$ emissions at the higher temperatures (and hence higher $\mathrm{NO}_{\mathrm{x}}$ levels) seen at TP2.

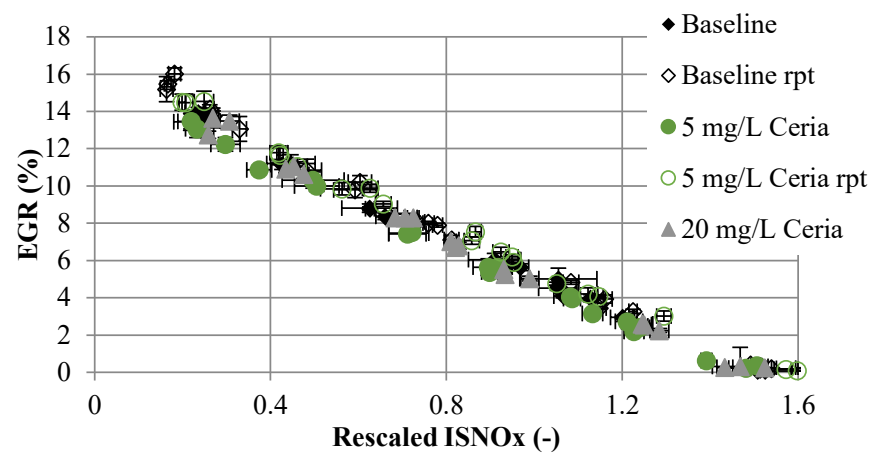

Figure 14: EGR vs ISNO for the fuels at TP2. The error bars correspond to $\pm \sigma$.

Figure 15 shows the ignition delay (defined here as time in crank angle degrees) between the main injection start of injection (MSOI) and the angle of $10 \%$ mass fraction burned (CA10) at TP2. As the ceria levels increase from $0-20 \mathrm{mg} / \mathrm{L}$ an increase in ignition delay of $\sim 5 \%$ for $5 \mathrm{mg} / \mathrm{L}$ ceria and $\sim 10 \%$ for $20 \mathrm{mg} / \mathrm{L}$ ceria can clearly be seen. It is not clear what is causing this ignition delay (which has not previously been reported in the literature) but it may be that it is caused by the time taken for the ceria to reach its active temperature, and its associated heat capacity removing heat from the incipient combustion. 


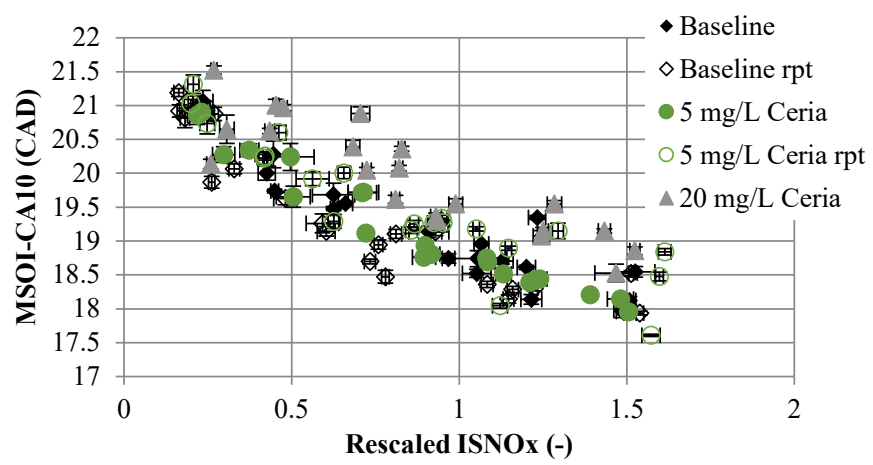

Figure 15: Ignition delay for the fuels at TP2. The error bars correspond to $\pm \sigma$.

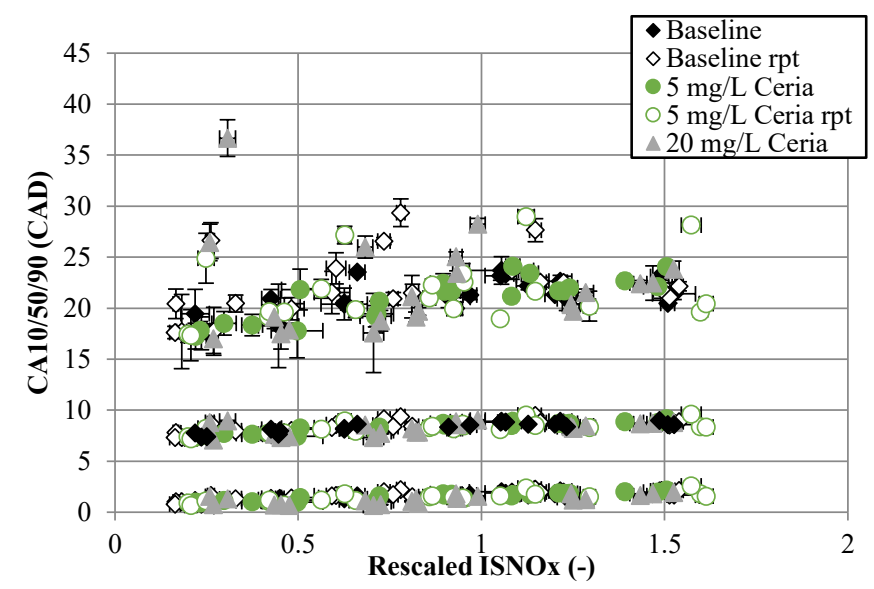

Figure 16: Burn rate analysis for the fuels at TP2. The error bars correspond to $\pm \sigma$.

Figure 16, Figure 17 and Figure 18 show the burn rate analysis, maximum cylinder pressure, and $\mathrm{NO}_{2} / \mathrm{NO}_{\mathrm{x}}$ ratio results respectively. Unlike at the low speed, low load test point, at this high speed, high load test point no significant differences are observed when dosing the fuels with ceria nano-particles. This is probably due to the high overall combustion temperatures experienced at this test point. It should be observed that because the engine is run with a fixed CA50 (see Table 2), and the injection timings modified to achieve this, the ignition delay results observed in Figure 15 do not affect the later burn rate (Figure 16) or $\mathrm{P}_{\text {Max }}$ (Figure 17) results as might otherwise be expected. 


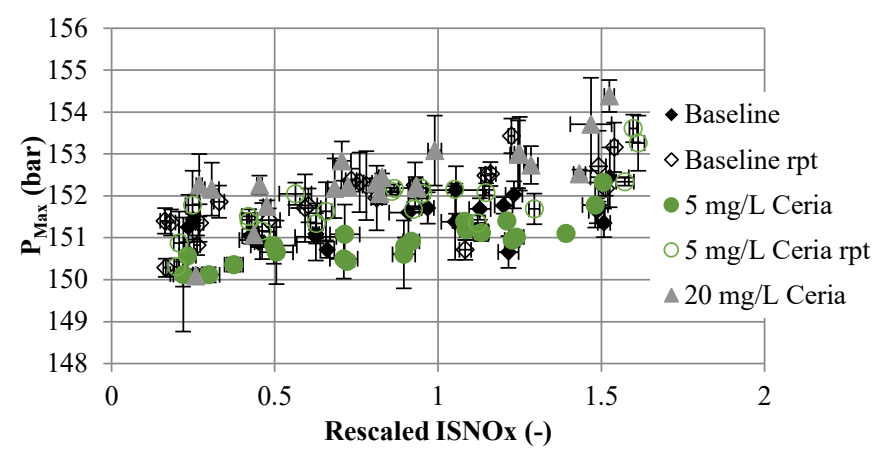

Figure 17: Maximum cylinder pressure for the fuels at TP2. The error bars correspond to $\pm \sigma$.

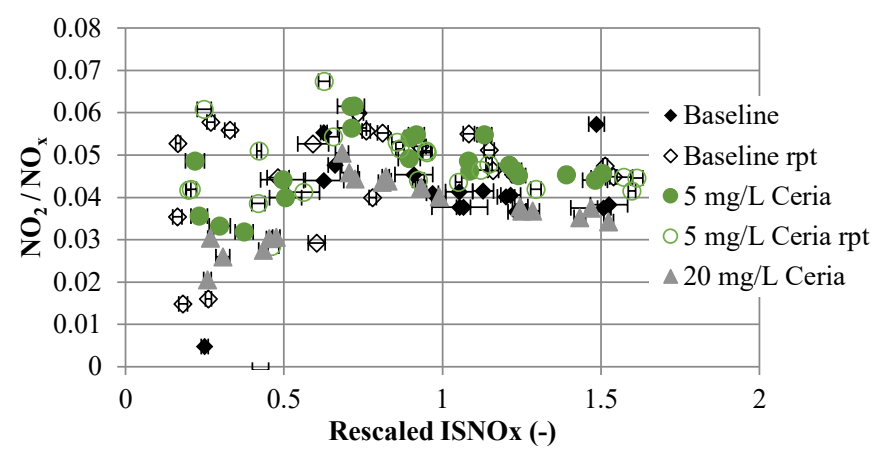

Figure 18: $\mathrm{NO}_{2} / \mathrm{NO}_{x}$ ratio vs ISNO for the fuels at TP2. The error bars correspond to $\pm \sigma$.

Figure 19 shows the particle size distributions for the fuels at TP2. In this figure, the standard deviations are omitted for clarity, but are of the same magnitude as those in Figure 10. As expected as the EGR rates increase, the overall levels of PN increase. However, at the higher levels of EGR a reduction in PN levels from the baseline with the fuels with ceria nano-particle dosing is seen, indicative of the oxidative effect of the ceria. At low levels of EGR when minimal soot is produced, a peak in PN emissions around $12 \mathrm{~nm}$ is seen with the fuels with ceria nano-particle. Although particulate measurement below $23 \mathrm{~nm}$ presents some challenges, the DMS500 has been demonstrated to be capable of this [27]. This size is consistent with the diameter of the dosed ceria nano-particles, and the number of particles in this peak corresponds to the dosing levels of those ceria nano-particles. As the EGR levels increase (and hence overall soot / particle levels) this peak decreases back to ambient levels, suggesting that those 
ceria nano-particles are acting as nuclei for particle formation during the combustion. Particle nucleuses at a small size will collide with other particles and adsorb volatile species accumulating into larger diameter particles [28]. Assuming that this is the case, these particles will have ceria cores - and with ceria's known catalytic properties, it is possible that these particles might oxidise at lower temperatures, providing a potential benefit to DPF regeneration. However, it must be noted that this is conjecture at the moment, and it was not possible to test for this during this work.

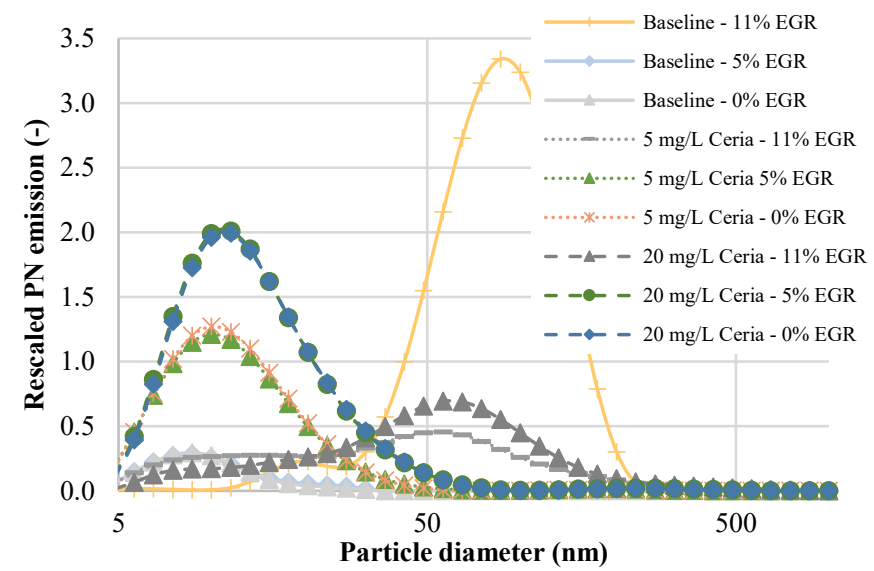

Figure 19: Particle size distributions for the fuels at TP2, varying EGR.

\section{Conclusions}

In this work the effect of dosing diesel fuel with $\mathrm{CeO}_{2}$ nano-particles on the combustion and emissions from a modern high-speed, light duty diesel research engine was investigated. Two dosing levels (5 mg/L and $20 \mathrm{mg} / \mathrm{L})$ were compared against an undosed diesel fuel over two engine test points and a range of EGR rates. Emissions, fuel consumption, and heat release results showed the following:

- The presence of $\mathrm{CeO}_{2}$ nano-particles in the fuel reduces soot emissions by up to $\sim 50 \%$ at some points at part load and high load. 
- At part load, a reduction ( $20 \%$ for $5 \mathrm{mg} / \mathrm{L}$ ceria and $\sim 30 \%$ for $20 \mathrm{mg} / \mathrm{L})$ in $\mathrm{HC}$ emissions is observed as well with the fuels dosed with $\mathrm{CeO}_{2}$ nano-particles in low temperature combustion.

- At high load there are no significant differences in HC emissions observed. No significant differences were seen in fuel consumption at either load/speed point. This contrasted with literature results, and is attributed to a lack of initial soot deposits in this work and benefits in DPF regeneration not being possible in this work due to the absence of a DPF.

- At high load, a $2-5 \%$ reduction in $\mathrm{NO}_{\mathrm{x}}$ for a given EGR level is observed with the fuels dosed with $\mathrm{CeO}_{2}$ nano-particles.

- A minor reduction $(\sim 2.5 \%)$ in peak cylinder pressure is observed with the fuels dosed with $\mathrm{CeO}_{2}$ nano-particles at part load, which is in line with previously reported results.

- At high load an increase in ignition delay of $\sim 5 \%$ for $5 \mathrm{mg} / \mathrm{L}$ ceria and $\sim 10 \%$ for $20 \mathrm{mg} / \mathrm{L}$ with the fuels dosed with $\mathrm{CeO}_{2}$ nano-particles is observed, again in line with previously reported results.

- The particle size distributions show particles consistent with the size of the dosed particles in the exhaust, but only at low levels of EGR when minimal soot is produced. At higher levels of EGR, given the lack of this peak observed at low EGR levels, it is thought that the $\mathrm{CeO}_{2}$ nano-particles are acting as nucleus for PN but no increase in overall PN is observed.

- At part load, in LTC, the fuels dosed with $\mathrm{CeO}_{2}$ nano-particles do not display the wide PN size distribution typically associated with LTC, and observed with the baseline fuel. The particle size distribution in LTC observed with the fuels dosed with $\mathrm{CeO}_{2}$ nanoparticles is of the same diameter as 'standard' diesel combustion modes, but at a lower overall level of PN. 
In the future it would be interesting to consider what effects dosing $\mathrm{CeO}_{2}$ nano-particles into diesel had on modern engine aftertreatment for example DOC, SCR, and DPF as well as catalyzed DPFs.

\section{References}

1. Younis, A., D. Chu, and S. Li, Cerium oxide nanostructures and their applications. Functionalized nanomaterials, 2016: p. 53-68.

2. Setiabudi, A., et al., CeO2 catalysed soot oxidation: The role of active oxygen to accelerate the oxidation conversion. Applied Catalysis B: Environmental, 2004. 51(1): p. 9-19.

3. Zhu, M., Y. Ma, and D. Zhang, Effect of a homogeneous combustion catalyst on the combustion characteristics and fuel efficiency in a diesel engine. Applied Energy, 2012. 91(1): p. 166-172.

4. Dai, M., et al., Experimental study on evaporation characteristics of diesel/cerium oxide nanofluid fuel droplets. Fuel, 2019. 254: p. 115633.

5. Blanchard, G., et al., Ceria-Based Fuel-Borne Catalysts for Series Diesel Particulate Filter Regeneration. SAE Technical Paper 2003-01-0378, 2003, doi:10.4271/2003-01-0378.

6. Andana, T., et al., Heterogeneous mechanism of NOx-assisted soot oxidation in the passive regeneration of a bench-scale diesel particulate filter catalyzed with nanostructured equimolar ceria-praseodymia. Applied Catalysis A: General, 2019. 583: p. 117136.

7. Mayer, A., et al., Retrofitting TRU-Diesel Engines with DPF-Systems Using FBC and Intake Throttling for Active Regeneration. SAE Technical Paper 2005-01-0662, 2005, doi:10.4271/2005-01-0662.

8. Kašpar, J., P. Fornasiero, and M. Graziani, Use of CeO2-based oxides in the three-way catalysis. Catalysis Today, 1999. 50(2): p. 285-298.

9. Heidari-Maleni, A., et al., Performance improvement and exhaust emissions reduction in diesel engine through the use of graphene quantum dot (GQD) nanoparticles and ethanol-biodiesel blends. Fuel, 2020. 267: p. 117116.

10. Venu, H., V.D. Raju, and L. Subramani, Combined effect of influence of nano additives, combustion chamber geometry and injection timing in a DI diesel engine fuelled with ternary (diesel-biodiesel-ethanol) blends. Energy, 2019. 174: p. 386-406.

11. Kazerooni, H., et al., Effects of Combustion Catalyst Dispersed by a Novel Microemulsion Method as Fuel Additive on Diesel Engine Emissions, Performance, and Characteristics. Energy \& Fuels, 2016. 30(4): p. $3392-$ 3402.

12. Bello, Y.H., et al., Investigating the engine performance, emissions and soot characteristics of CI engine fueled with diesel fuel loaded with graphene oxide-titanium dioxide nanocomposites. Fuel, 2020. 269: p. 117436.

13. Wakefield, G., et al., Envirox ${ }^{\mathrm{TM}}$ fuel-borne catalyst: Developing and launching a nano-fuel additive. Technology Analysis \& Strategic Management, 2008. 20(1): p. 127-136.

14. Zhang, Z., et al., Comparative study of using multi-wall carbon nanotube and two different sizes of cerium oxide nanopowders as fuel additives under various diesel engine conditions. Fuel, 2019. 256: p. 115904.

15. Stagecoach. Stagecoach cuts carbon emissions through innovative fuel saving additive, 2013. Available from: https:/www.stagecoach.com/media/news-releases/2013/2013-03-07-stagecoach-cuts-carbon-emissions-throughfuel-saving-additive.aspx. Accessed 28.09.2020

16. Zhang, J., et al., Impacts of a Nanosized Ceria Additive on Diesel Engine Emissions of Particulate and Gaseous Pollutants. Environmental Science \& Technology, 2013. 47(22): p. 13077-13085.

17. Pandey, A.K., et al., The Effect of Cerium Oxide Nano Particles Fuel Additive on Performance, Combustion, NOx Reduction and Nano Particle Emission of Karanja and Jatropha Biodiesel in a Military $585 \mathrm{~kW}$ CIDI Engine.

SAE Technical Paper 2019-01-0262, 2019, doi:10.4271/2019-01-0262..

18. Khalife, E., et al., A novel emulsion fuel containing aqueous nano cerium oxide additive in diesel-biodiesel blends to improve diesel engines performance and reduce exhaust emissions: Part I - Experimental analysis. Fuel, 2017. 207: p. 741-750.

19. Miles, P.C. and Ö. Andersson, A review of design considerations for light-duty diesel combustion systems. International Journal of Engine Research, 2015. 17(1): p. 6-15.

20. Papaiouannou, N., et al., Evaluation of EGR techniques on a HSDI diesel engine using first law analysis. Proceedings of the Institution of Mechanical Engineers, Part D: Journal of Automobile Engineering, 2018. 233(3): p. $710-726$ 
21. Leach, F., et al., Comparing the Effect of Fuel/Air Interactions in a Modern High-Speed Light-Duty Diesel Engine. SAE Technical Paper 2017-24-0075, 2017, doi:10.4271/2017-24-0075.

22. Leach, F., R. Ismail, and M. Davy, Engine-out emissions from a modern high speed diesel engine - The importance of Nozzle Tip Protrusion. Applied Energy, 2018. 226: p. 340-352.

23. Leach, F., et al., Comparing the effect of a swirl flap and asymmetric inlet valve opening on a light duty diesel engine. SAE Technical Paper 2017-01-2429, 2017, doi:10.4271/2017-01-2429.

24. EN590, British Standards BS EN 590 Diesel, Requirements and Test Methods. 2009.

25. Rößler, M., et al., Formation of Engine Internal NO2: Measures to Control the NO2/NOX Ratio for Enhanced Exhaust After Treatment. SAE International Journal of Engines, 2017. 10(4): p. 1880-1893.

26. Leach, F., M. Davy, and M. Peckham, Cyclic NO2:NOx ratio from a diesel engine undergoing transient load steps. International Journal of Engine Research. doi:10.1177/1468087419833202

27. Leach, F., et al., Sub-23 nm Particulate Emissions from a Highly Boosted GDI Engine. SAE Technical Paper 2019-24-0153, 2019, doi:10.4271/2019-24-0153.

28. Eastwood, P., Particulate Emissions from Vehicles. 2008: SAE International and John Wiley \& Sons, Ltd.

\section{Contact Information}

Felix Leach

Department of Engineering Science,

University of Oxford,

Parks Rd,

Oxford,

OX1 3PJ,

UK

Email: felix.leach@eng.ox.ac.uk

\section{Acknowledgments}

The authors would like to thank the Jaguar Land Rover Limited and University of Oxford John Fell fund for financial support. Energenics Europe Ltd. are thanked for technical support and supplying Envirox ${ }^{\mathrm{TM}}$ - the cerium oxide nanoparticles. The authors would also like to thank the Dept. of Engineering Science technicians and maintenance teams for facilities support 